\title{
pÿExplaining university students strong commitment to understand through individual and contextual elements
}

\section{Postareff, Liisa}

2014

pÿPostareff , L , Lindblom-Ylänne , S \& Parpala , A 2014 , ' Explaining university students strong commitment to understand through individual and contextual elements ', Frontline Learning Research, vol. 2 , no. 1 , pp. 31-49 . https://doi.org/10.14786/flr.v2i1.63

http://hdl.handle.net/10138/232939

https://doi.org/10.14786/flr.v2i1.63

cc_by_nc_nd

publishedVersion

Downloaded from Helda, University of Helsinki institutional repository.

This is an electronic reprint of the original article.

This reprint may differ from the original in pagination and typographic detail.

Please cite the original version. 


\title{
Explaining university students' strong commitment to understand through individual and contextual elements
}

\author{
Liisa Postareff ${ }^{\text {a }}$,Sari Lindblom-Ylänne ${ }^{a}$ \& Anna Parpala ${ }^{a}$ \\ ${ }^{\text {a } U n i v e r s i t y ~ o f ~ H e l s i n k i, ~ F i n l a n d ~}$
}

Article received $20^{\text {th }}$ September $2013 /$ revised $14^{\text {th }}$ February 2014 / accepted $20^{\text {th }}$ February 2014 / available online $25^{\text {th }}$ April 2014

\begin{abstract}
Since the late 1970s numerous studies have explored students' approaches to learning (referred to as the 'SAL' tradition). These studies have provided valuable evidence of students' study strategies and intentions at the university. Since extensive research already exists on students' approaches to learning, there is a need to move forward and analyse student learning from new perspectives. In the present in-depth qualitative study, we analyse interviews of 34 students who scored extremely highly on the deep approach scale in a pre-test in our previous quantitative study (Lindblom-Ylänne, Parpala \& Postareff, 2013) and thus are likely to have a strong commitment to understand, and a 'disposition to understand for oneself' which is a recently introduced, yet unexplored phenomenon (see Entwistle \& McCune, 2009; McCune \& Entwistle, 2011). We identified several individual and contextual elements which provided explanations for the students' high scores on the deep approach, as well as for the increase, decrease or stability in their deep approach during one course. The results showed that most students showed a strong commitment to understand, but those whose deep approach sharply decreased during the course showed less commitment and their descriptions revealed problems with, for example, study skills, time management and regulation of learning. However, contextual elements such as the students' experiences of the course teaching and their interest in the course content did not clearly provide explanations for the changes in the deep approach. Elements of a 'disposition to understand for oneself' clearly emerged among students whose deep approach did not decrease, or decreased only slightly.
\end{abstract}

Keywords: Approaches to Learning, Disposition to understand for oneself, Commitment to understand, Higher Education 


\section{Introduction}

Numerous studies which have been conducted within the SAL (Students Approaches to Learning; see Lonka, Olkinuora, \& Mäkinen, 2004) tradition have identified three qualitatively different approaches to learning: the deep and surface approaches (e.g., Biggs, 1987; Entwistle \& Ramsden, 1983; Marton \& Säljö, 1976, 1997) and strategic approach or organised studying (e.g. Biggs, 1987; Entwistle \& Ramsden, 1983). A deep approach to learning has been shown to be related to high-quality learning outcomes (Diseth 2003; Watters \& Watter 2007), and therefore university students are encouraged to aim at constructing meaning and develop deep understandings of the study content. However, research has shown that students vary to a great extent with regard to their approaches to learning in that some are more likely to adopt deep approaches while others will rely more on surface learning. Moreover, most students' approaches seem to vary depending on the context (e.g. Vermunt, 1998; Nieminen et al., 2004, Lindblom-Ylänne et al., 2012). Recent research has further suggested that some students continually aim at a deep understanding and thus have a disposition to understand for oneself (Entwistle and McCune 2009; McCune and Entwistle, 2011).

The disposition to understand is a more consistent and stronger form of the 'intention to understand' found in a deep approach to learning. Students with such a disposition aim at reaching a full and satisfying understanding of what they study. Entwistle and McCune suggest that a disposition to understand is an important characteristic for students to develop at university in order to cope with the uncertainty and complexity of society in the future. The disposition to understand contains three central elements: 1) a welldeveloped use of learning strategies which concentrate on relating ideas, the critical use of evidence and attention to detail; 2) a willingness to devote the necessary time, effort, and concentration to apply the learning strategies effectively; and 3) an alertness to the learning context (Entwistle \& McCune 2009; McCune \& Entwistle, 2011). These three elements are similar to the ones Perkins and Tishman (2001) identified when exploring 'thinking dispositions'. Thinking dispositions are stable ways of reacting to situations and thinking critically, and are comprised of three components needed in carrying out intellectual tasks: willingness to apply effort, ability to perform the task effectively, and alertness to situations in which thinking is required. Entwistle and McCune (2009) took this avenue, when analysing students' approaches to learning and disposition to understand.

The disposition to understand is a broader concept than the deep approach to learning. While a deep approach describes the student's intention to understand the content of study and the use of effective learning strategies, such as relating ideas and using evidence (e.g. Entwistle \& Ramsden 1983; Marton \& Säljö, 1997), the disposition to understand focuses more broadly on a specific discipline as a whole. A student with a strong disposition to understand for oneself shows an emotional commitment to continuously strive towards understanding and to monitor the development of understanding the contents of study (Entwistle \& McCune 2009; McCune \& Entwistle, 2011).

Empirical studies on the disposition to understand for oneself are rare. Still, in a recent study Entwistle and McCune (in press) analysed nearly 2000 students from undergraduate courses and aimed to identify students who showed high and consistent scores for a deep approach to learning, as well as for organised effort and monitoring studying. They found one cluster of students whose scores were high on all these scales and remained stable over time, thus showing characteristics of a disposition to understand. The other clusters also scored high on the deep approach, but in addition showed surface elements, or lower scores on organised effort or monitoring studying. To our knowledge, this quantitative study is the only empirical one conducted on students' disposition to understand.

What especially differentiates a disposition to understand from a deep approach is that the former is characterised as more stable (Entwistle and McCune 2009; McCune \& Entwistle, 2011) while the latter has been characterised as more contextual and changeable (e.g., Vermunt, 1998; Nieminen et al., 2004, Lindblom-Ylänne et al., 2013). However, opposite views have also been presented, as the deep approach has been claimed to be a relatively stable construct (e.g., Lietz \& Matthews, 2010; Zeegers, 2001) but the mainstream conception seems to rely on the original view of the contextual and dynamic nature of the approaches presented by Marton and Säljö already in 1976. A deep approach to learning seems to be difficult to induce since a number of quantitative studies have shown a decrease in the deep approach after varying 
study periods. Some studies have shown a decrease in the deep approach after a three-year study period (Biggs, 1987; Watkins \& Hattie, 1985) and others have shown a decrease after shorter course units (e.g., Lindblom-Ylänne et al., 2013).

Evidence shows that inducing a deep approach to learning might be difficult even in student-centred learning environments (e.g. Gijbels, Segers, \& Struyf, 2008; Struyven, Dochy, Janssens, \& Gielen, 2006). However, in a number of quantitative studies it has been shown that satisfaction with the quality of a course as well as a student-centred approach taken by teachers has been shown to enhance the application a deep approach (Trigwell, Prosser, \& Waterhouse., 1999; see also Baeten, Kyndt, Struyven, \& Dochy, 2010). In addition, individual reasons such as intrinsic motivation, self-confidence, strong self-efficacy beliefs and openness to experience have been shown to enhance the adoption of a deep approach (Baeten et al., 2010; Kyndt, Dochy, Cascallar, \& Struyven, 2011).

The changes in a deep approach and the individual and contextual factors affecting its adoption have thus been explored in a number of quantitative studies, but to our knowledge no qualitative research combining these two elements has been carried out. This study presents an in-depth qualitative analysis of the factors explaining the stability or changes in a deep approach to learning among students who scored extremely highly on a deep approach scale in the pre-test. The existence of the disposition to understand for oneself is also explored. Thus the study provides both methodologically and theoretically a fresh perspective on research on student learning in higher education.

\subsection{Aims of the study}

The study aims to more deeply understand the results from previous research of ours which concentrated on analysing with quantitative methods group-level changes in one's deep approach during different courses (Lindblom-Ylänne et al., 2013). The pre-test/ post-test results showed large individual variation in all disciplinary contexts in terms of the amount and direction of change in students' deep approach to learning. The present study concentrates on analysing interviews of students who scored the highest on a deep approach scale in the pre-test. The aim is to identify the individual and contextual elements which are related to a strong commitment to understand as shown in the pre-test, and also to the stability or decrease in one's deep approach during the course as shown in the post-test. In addition, the study provides a new perspective on analysing approaches to learning as it focuses on exploring the existence of the disposition to understand for oneself. Thus the second aim is to analyse how a disposition to understand for oneself emerged from the interviews. Previous work on the disposition to understand for oneself has not been based on coherent evidence, and has not been empirically conducted with diverse samples of students (see Entwistle \& McCune, 2009). Thus the present study aims to provide empirical evidence of the disposition to understand through an in-depth qualitative analysis of student interviews.

\section{Materials and methods}

The study adopts a mixed-methods approach as it has its roots in the quantitative results, which are then explained through analysing student interviews. Mixed methods research is a type of research in which elements of qualitative and quantitative research approaches are combined in order to gain a deep and broad understanding of the phenomenon under study (see e.g. Johnson, Onwuegbuzie \& Turner, 2007). Cresswell (2009) emphasises that the use of mixed methods approach has its roots in pragmatism, in which the most important thing is to focus attention on the research problem itself and use pluralistic approaches to derive knowledge about the problem. An advantage of using mixed methods is that the results from one method can help develop or inform other methods. In the present study we adopted a sequential procedure through which we attempted to elaborate on and expand the quantitative findings with the qualitative ones (see Creswell, 2013).

In addition, the study adopts, along with a traditional variable-oriented technique, a person-oriented approach, which assumes that human behavior is affected by several factors and the interplay between these 
several factors forms unique profiles of individuals (see Vanthournout et al., 2013). The person-oriented approach is sometimes considered as an opposite to variable-oriented techniques, but they should be more viewed as complementary techniques (Vanthournout et al. 2013). In the present study both techniques are used to provide complementary information (see section 2.3).

\subsection{Participants and contexts of the study}

The participants of the study were selected among 277 Bachelor students from the University of Helsinki, who took part in our previous quantitative study (Lindblom-Ylänne et al., 2013). The 34 students were selected on the basis of having scored extremely highly on a scale measuring their deep approach to learning. The students were categorised into three groups on the basis of how their deep approach to learning changed between two measurements (at the beginning and at the end of a course). The present study focuses on analysing interviews of the students in these three change groups. In the following chapter, we provide some insight into our previous quantitative study and into the procedure of creating the change groups in order to create an understanding of the inventory results and of the differences between the three groups of students. A more detailed description of the quantitative analyses is provided in our previous study (Lindblom-Ylänne et al., 2013).

\subsubsection{Background for selecting the participants}

For the previous studies, the data were collected from 10 Bachelor-level courses in five different disciplines. The students of the courses completed the Approaches to Studying and Learning Inventory (ALSI; see section 2.2.) at the beginning and at the end of a lecture course. At the beginning of the course the students were asked to consider how they had studied in their major up until then, and at the end of the course they were asked to focus on how they had studied in that particular course. Their scores at the beginning and at the end of the course were used to explore changes in their approaches to learning between the two measurements At the beginning of the courses the mean of the deep approach scale in each discipline varied from 3.42 to 3.66 on a scale of 1 to 5, and at the end of the courses the range was from 3.07 to 3.24. In each discipline, the decrease in the deep approach between the two measurements was statistically significant. A paired-samples t-test showed that the t-values ranged from 2.25 to 4.86 and the p-value varied between 0.001 and 0.028. Among Bioscience students the decline was the lowest being -0.15 , while among Mathematics students the decline was the highest being -0.35 .

After exploring the differences between the two measurements at the group level, we wanted to explore the changes at a more individual level. We computed the deep approach change variables by subtracting the students' scale scores at the end of the course from their scale scores at the beginning of the course. The magnitude and the direction of the change served to create five groups of change (see Table 1): strong increase, increase, no change, decrease and strong decrease. The distributions of the change variables were explored in detail in order to decide upon the best cutting points for the change groups. Our decision was to create the change groups on the basis of Likert-scale point changes, which is a procedure followed previously by Lindblom-Ylänne, Trigwell, Nevgi \& Ashwin (2006). The benefit of using change variables is that they mirror the absolute changes instead of relational changes. Our purpose was to focus on the changes of individual students regardless of other students' values. We used a quarter of a Likert scale as the cutting point between the change groups in order to separate different types of changes in as detail as possible. A half of a Likert scale would have been too robust, since a decrease of 0.15 in the deep approach was already statistically significant. We also considered categorisation on the basis of standard deviation or median split, but these are based on relational values and they would have rendered a comparison of the changes between the three approaches impossible (which was the focus in our previous study, see Lindblom-Ylänne et al., 2013). For the present study, the 34 students were divided into three subgroups on the basis of the change variable categories: 1) deep approach remains high (includes the 'no change' and the 'increase' groups), 2) slight decrease in one's deep approach and 3) sharp decrease in one's deep approach. 
Table 1

\section{Change variable categories}

\begin{tabular}{ll}
\hline The direction of change & Differences in scores \\
\hline Sharp increase in the approach to learning & 0.50 or higher \\
Slight increase in the approach to learning & From 0.25 to 0.49 \\
No change & From -0.24 to 0.24 \\
Slight decrease in the approach to learning & From -0.25 to -0.49 \\
Sharp decrease in the approach to learning & -0.50 or lower \\
\hline
\end{tabular}

After creating the change groups, the students were divided into four ranked percentile groups based on their deep approach scores at the beginning of the course. The 34 students who were selected for the present study were categorised into the highest-ranked percentile group at the beginning of the course. Their deep approach score at the beginning of the course was between 4.00 and 5.00 which is remarkably higher than the mean score of the deep approach in any of the disciplines. Thus the selected students were among the highest scoring students in the deep approach scale. While the students' deep approach scores at the beginning of the course varied between 4.00 and 5.00, the variation at the end of the course was between 1.5 and 5.00. Nine students were categorised into the 'deep approach remains high' group. Of them, four students showed increase in the deep approach, while five students' scores remained exactly the same. Seven students were categorised into the 'slight decrease in deep approach' group. These students' deep approach scores at the beginning of the course varied between 4.00 and 5.00, and all of them scored 0.25 lower on the deep approach scale at the end of the course. The 'sharp decrease in the deep approach' group consisted of 18 students, whose deep approach scores at the beginning of the course varied between 4.00 and 5.00 , and at the end of the course between 1.5 and 4.50. The decrease in their deep approach was between -0.5 and -3.25 . However, in only five cases was the decrease more than -1.00 .

\subsubsection{Participants and contexts}

Of the 34 students, 21 were female and 13 male. They ranged in age from 19 to 43 years, the mean age being 27. In Finland, students' mean age is higher than in most European countries because students graduate from upper secondary school later and thus enter university at an older age than in most European countries. However, the mean age of 27 years is higher than the average among Bachelor students. Two of the students were minoring in the courses while the rest were major students.

The 34 students were attending a compulsory Bachelor-level course in their own discipline (except for the two students who were minor students), and each was interviewed after completing the course. The students participated in one of 10 courses representing five disciplines: three courses in bioscience ( $\mathrm{n}=7$ ), two in educational sciences $(n=12)$, one in mathematics $(n=2)$, three in theology $(n=10)$ and one in veterinary medicine $(n=3)$. The courses are presented in Table 2. The courses were designed for second year students, except for courses on educational sciences which were designed for first year students. All ten courses were lecture courses that included both lecturing and activating assignments for the students, with the nature of the assignments varying. The courses lasted from 6 to 13 weeks and were worth between 3 and 10 credits. Eight courses included a written exam at their conclusion, while one course included a learning diary and an oral exam, and one included a drama-type exam. An effort was made to select as similar courses as possible from the point of view of the students' role in order to minimise the effect of the course itself on the results. However, one course was based on group activities, and the exam was a group exam. In another course, the exam was a group exam in drama form. Thus two courses differed from the others because they were based more on group activities, while the rest were based on individual tasks and exams. In all courses the students attended in lectures and completed some activating tasks. 
Table 2

The discipline and course of the participants

\begin{tabular}{|c|c|c|c|}
\hline Discipline & Course & Students (n) & Course type and assessment \\
\hline \multirow[t]{3}{*}{ Bioscience } & Course 1 & 3 & Lectures, written exam at the end \\
\hline & Course 2 & 3 & Lectures, written exam at the end \\
\hline & Course 3 & 1 & Lectures, written exam at the end \\
\hline \multirow[t]{2}{*}{ Educational sciences } & Course 1 & 7 & $\begin{array}{l}\text { Peer group working, short lectures, oral exam and } \\
\text { learning diary }\end{array}$ \\
\hline & Course 2 & 5 & Lectures, written exam at the end, essay \\
\hline Mathematics & Course 1 & 2 & Lectures, calculations, written exam at the end \\
\hline \multirow[t]{3}{*}{ Theology } & Course 1 & 3 & $\begin{array}{l}\text { Lectures (including lots of discussions) written } \\
\text { exam at the end }\end{array}$ \\
\hline & Course 2 & 6 & Lectures, written exam at the end \\
\hline & Course 3 & 1 & $\begin{array}{l}\text { Lectures (including much discussions), drama-type } \\
\text { exam at the end }\end{array}$ \\
\hline Veterinary medicine & Course 1 & 3 & Lectures, written exam at the end \\
\hline
\end{tabular}

\subsection{Materials}

The students were interviewed on a voluntary basis once the courses had concluded. They were told beforehand about the content and purpose of the interview, and at the beginning of the interview they were allowed to ask questions about the research or the interview. The interviewees were told about the confidentiality of the interviews and that they cannot be identified at any point. The interviews were held in autumn 2009, autumn 2010, or spring 2011. Conducted by the first author and two research assistants, the interviews lasted from 35 to 75 minutes and were transcribed verbatim. The interviews focused on the students' descriptions of their intentions and goals related to studying and learning at the university, their learning processes and practices in general as well as during the course they had just completed, and their experiences of studying and learning in the specific course they had recently attended. The interviews were deep and open in nature, with each of them covering the above-mentioned theme.

For our previous study (Lindblom-Ylänne et al., 2013), which formed the basis for selecting the students for the present one, the students filled in a revised version of the ALSI (Entwistle \& McCune, 2004; Parpala \& Lindblom-Ylänne, 2012) which contains scales measuring students' approaches to learning. The deep approach scale consists of four items, which are presented in Table 3. Items 1 and 2 measure students' learning strategies while items 3 and 4 focus on their intentions. In the interviews, the focus was similarly on students' study strategies and intentions. 
Table 3

Items on the deep approach scale

\begin{tabular}{ll}
\hline Item 1 & Ideas I've come across in my academic reading set me off on long chains of thought. \\
Item 2 & I look carefully at evidence to reach my own conclusion about what I'm studying. \\
Item 3 & I try to relate new material, as I am reading it, to what I already know on the topic. \\
Item 4 & I try to relate what I learn in one course to what I have learned in other courses.
\end{tabular}

\subsection{Analyses}

Qualitative content analysis was selected as the analysis method for the interview data. In the first phase, we used inductive content analysis, in which themes are allowed to emerge from the data without any theoretical assumptions (see Elo \& Kyngäs, 2007; Schilling, 2006). Inductive content analysis was used to analyse how the students described their studying and learning (both generally in their university studies and in the specific course), as well as their study experiences during the specific course. Three steps typical of inductive content analysis were carried out: data reduction, grouping and conceptualisation (see Patton, 1990; Flick, 2002). These three steps represented the variable-oriented technique (see Vathournout et al., 2013) as the aim was to identify all factors related to students' learning and study experiences regardless of the individuals. The first step was data reduction, in which all descriptions related to these issues were identified from the interview transcripts. This was done by the first author independently. The second step was to group similar descriptions under same categories (e.g., all descriptions related to students' motivation were placed under the same category). This was done by the first and second author independently, and the identified categories were compared and discussed. After an in-depth discussion, the identified descriptions were placed under seven categories. The third step, conceptualisation, included finding a concept for each of the seven categories which describe the content and nature of each category. For example, the category including description related to emotions and attachment was conceptualised as 'emotional commitment'. This was done in collaboration with all three authors.

In the second phase of the analysis a person-oriented approach was adopted (see Vanthournout et al., 2013). Each of the seven categories was investigated in more depth within the following three groups of students: 'deep approach remains high', 'slight decrease in deep approach', and 'sharp decrease in deep approach' in order to identify similarities and differences within students in the same group and between students in different groups. For example, we explored how students showing sharp decrease in their deep approach described their motivation, emotional commitment, and the remaining five categories, and compared their descriptions to other students' descriptions. This phase was conducted by the first author, but the final results were obtained through a thorough discussion with all three authors.

The third phase of the analysis was deductive content analysis, in which existing theories are utilised in analysing the data (see Elo \& Kyngäs, 2007; Schilling, 2006). In this phase we analysed, through adopting a person-oriented approach, how the three central elements of the disposition to understand emerge in each students' interview: 1) a well-developed use of learning strategies which concentrate on relating ideas, the critical use of evidence and attention to detail; 2) a willingness to devote the necessary time, effort, and concentration to apply the learning strategies effectively; and 3) an alertness to the learning context (see Entwistle \& McCune 2009; McCune \& Entwistle, 2011). This phase was conducted independently by the first two authors. The findings of both authors were compared and discussed together. The inter-rater agreement was high, although several discussions were needed to obtain the final results. To give an example, the 'emotional commitment' category was discussed in depth to determine which elements would be included in it. 


\section{Results and Discussion}

In each of the three groups, elements related to the high level of a deep approach at the beginning of the course were analysed. In addition, students' descriptions of studying and learning in the specific courses were analysed separately in each group. In each of the groups the elements related to stability or changes in one's deep approach could be categorised under seven different themes: 1) Students' motives, intentions and study strategies, 2) organised studying and regulation of learning, 3) emotional commitment, 4) experiences of challenge, 5) interest in the course content, 6) devoting time and effort to studying during the course and 7) experiences of the course teaching. These were identified in each of the three groups. Finally, elements of a 'disposition to understand for oneself' were identified.

In what follows, the seven themes identified in the student interviews are described and discussed within each of the following categories of change: 'remains high', 'slight decrease' and 'sharp decrease'. Finally, the results concerning a disposition to understand are presented and discussed.

\subsection{Individual and contextual elements related to one's deep approach to learning}

Both individual and contextual elements related to the stability or changes in one's deep approach to learning were identified. However, clearly distinguishing between individual and contextual elements was challenging because, for example, the category 'devoting time and effort to studying during the specific course' combined the individual's effort and the context. The range of elements is presented from individual to more contextual ones below.

\subsubsection{Students' motives, intentions and study strategies}

When describing their studying and learning in general, the nine students whose deep approach scores remained high described having a strong intrinsic motivation to study at the university. They said that it is not enough for them to just pass courses, but that they aim at a deep understanding of the subject matter and developing themselves as persons. Marton, Dall'Alba and Beaty (1993) found a similar category, 'changing as a person', and van Rossum, Deijkers and Hamer (1985) labelled another similar category as 'self realisation'. The nine students' descriptions revealed that their conceptions of learning were sophisticated, including, for example, conceptions of learning being about relating ideas and combining new information with their previous knowledge. Some of the students also stated that when they are able to explain the subject to someone else in their own words, they feel they have learned well. These students' descriptions revealed that they all had developed good and functional study skills. They all concentrated on the big picture instead of details, and explained that they had formed a larger picture of the learned material for themselves. The students' descriptions revealed that they go through deep thinking processes while studying. These students' descriptions of their studying were therefore in line with the inventory results in that they clearly reflected an adoption of a deep approach to learning: their intention was to learn deeply and to form a coherent whole from the subject matter, and they used strategies which enabled deep-level learning (see e.g. Entwistle, 2009).

The seven students showing a slight decrease in their deep approach to learning described their studying and learning at the university very similarly to the students showing no deep approach decrease. In addition, all seven students in this group seemed to have a strong intrinsic motivation towards their university studies. They emphasised that learning is about broadening one's understanding and observing things from new perspectives. Integrating new information with previous knowledge was also emphasised. All six students' descriptions revealed that they had good study skills as did the students showing no deep approach decrease. The students stated, for example, that they analyse the subject matter from diverse perspectives and explain the central concepts or content in their own words. Most mentioned that they search for extra material by themselves and concentrate on what they find challenging. In addition, most also mentioned using a variety of learning strategies (e.g. mind maps, notes, explaining things in their own words). None of the students described difficulties in their learning. Two of the seven mentioned preparing for lectures beforehand through familiarising themselves with the content. Thus the students showing a slight 
deep approach decrease were aiming at a deep understanding, and used effective strategies to accomplish this, being in this sense very similar to the students showing no decrease.

The 18 students showing a sharp deep approach decrease differed more from the two other student groups. Firstly, six of them described more extrinsic motivators (such as earning a degree), although they also mentioned that they like studying at the university and that in most occasions they are also interested in course content. Secondly, not all students in this group described applying a deep approach to learning as strongly as those in the two other groups. For example, one characterised her study process as mainly memorising things. Although most students' descriptions reflected elements of deep learning, only three described themselves learning as deeply as students in the two other groups. Moreover, three students mentioned uncertainty regarding their own way of learning as well as feelings of incompetence. Two of these students described their learning in a very theoretical manner, rather than in their own words; thus their awareness of the elements of deep learning as students in educational sciences might have contributed to their high score on the deep approach scale at the beginning of the course. The third student stated that she would like to 'learn how to learn'. These three students seemed to have problems with their study skills. However, the other students' interviews did not reflect such problems. These results imply that the more varying motives, intentions and study strategies among some of the students in this group might be related to a decrease in their deep approach to learning. While students showing a slight or no decrease had a commitment to learn, the interviews of students showing a sharp decrease did not reflect such a clear commitment. There were no clear differences between students participating in different courses with regard to their intentions, motives and study strategies, except that two students in a an educational sciences course described their learning in a way which implied that they were aware of theories of learning when describing their own studying. However, this difference was related more to the students' discipline than to the course itself.

\subsubsection{Regulation of learning}

The descriptions of the nine students whose deep approach scores remained high revealed that they all had good self-regulation skills. Self-regulation refers to processes in which students plan, monitor, control and regulate their own learning (Vermunt, 1998). Self-regulation resembles organised studying (Entwistle \& McCune, 2004), making the two concepts partly overlap. For example, time-management skills can be related to organised studying or self-regulated learning. All nine students described setting goals for their own learning, and studying regularly instead of only before deadlines or exams. They wanted to learn the course content deeply, and they read additional material or consulted their teachers or peers when they had difficulties in understanding the content. They all attended lectures regularly, although attendance was voluntary in all courses. Thus they clearly assumed responsibility for their own learning. Scheduling studies beforehand was also emphasised by some of the students. They all described having good time-management skills although one student mentioned sometimes having difficulties in getting started. Some of these students emphasised that they concentrate on the most relevant content and study effectively in order to avoid an overload of work. The interview results support the results of previous studies showing that selfregulation is related to a deep approach to learning (e.g. Lonka \& Lindblom-Ylänne, 1996; Heikkilä \& Lonka, 2006; Heikkilä et. al., 2011; Vermunt \& van Rijswijk, 1988). Self-regulation skills are also related to students' study pace, study success and well-being (e.g. Heikkilä et. al., 2011; Rytkönen et. al., 2012).

The seven students showing slight decrease in the deep approach also seemed to have good selfregulation skills. Their descriptions implied that they were aware of what they were supposed to learn and were able to focus their attention on the relevant content. They all studied on a regular basis, but a very organised way of scheduling own studies was mentioned by only one student, which clearly differentiated her from the three students showing no decrease in the deep approach. Three of these students mentioned that they do not attend lectures regularly, but instead devote their time to reading the course material. However, none of these students' interviews reflected clear problems with self-regulation skills.

The 18 students whose deep approach decreased sharply clearly differed from the two other groups with regard to self-regulation skills. Only five students' descriptions reflected good self-regulations skills. The remaining 13 students' descriptions did not reflect severe problems in self-regulation, but most of these 
students had not, for example, set goals for their own learning, and four of them expected concrete guidance and support from the teacher. Thus a lack of regulation or external regulation characterised these students more than self-regulated learning. Externally regulated students rely on teachers, other students or study material for guidance, while lack of regulation relates to difficulties in self-regulation. Students who lack self-regulation skills are unsure about how they should study or may find it difficult to assess whether they have sufficiently learned the subject matter (Vermunt, 1998; Vermunt \& Verloop, 1999). Furthermore, the 13 students in this group did not describe organising their studies systematically, and their time management skills were not as good as those whose deep approach did not decrease. Two students had more severe problems concerning time-management and organising their studies effectively. For example, one described trying to find a rhythm and routine in her studies and avoid doing things right before the deadlines. These problems in self-regulation skills and time management are likely to explain the decrease in these students' deep approach, and may also reflect a combination of unorganised studying and applying a deep approach in an overly sense (see Parpala et al., 2010). There were no differences between students participating in the different courses with regard to their self-regulation skills.

\subsubsection{Emotional commitment}

All nine students whose deep approach remained high described being committed to their studies. However, six of those students described stronger emotions related to studying their major subject, i.e. having a strong attachment to and respect for the subject they were studying. They also mentioned having a desire to learn more about the discipline and enjoying the university experience as well as pride in studying at the university. A recent quantitative study similarly showed a relationship between university students' positive emotions, such as pride, and a deep approach to learning (Trigwell, Ellis \& Han, 2011).

Of the seven students showing a slight deep approach decrease, only one mentioned strong emotions and an attachment to studying her discipline, or a desire to do so. Enjoyment of learning was mentioned by four students in this group, but none of the seven described their studying in a negative light. The results show that these students did not have such a strong emotional commitment towards studying as did their peers whose deep approach did not decrease.

All 18 students showing a sharp deep approach decrease described enjoying their studies in general, but a majority of these students mentioned it being very context-dependent. In some courses they are very committed, but in others they simply want to do the minimum in order to pass the course. Only one of the 18 students described having a strong attachment or desire with respect to her studies. She stated that it is important for her to be part of the scientific community. To conclude, enjoyment of learning was mentioned by all 34 students, but clear differences were noted between the students' emotional commitment with regard to the changes in their deep approach to learning. Again, there were no differences between students participating in the different courses with regard to their emotional commitment.

\subsubsection{Devoting time and effort to studying during the specific course}

Eight of the nine students whose deep approach remained high during the courses devoted considerable time to studying the course content, and they described studying actively in all the courses they take. Most of them said that they did not have to invest much time in preparing for the exam because they had studied thoroughly throughout the entire course. Some mentioned that the course content was challenging, or that the lecturer proceeded too quickly, which compelled them to devote even more time and effort than normally. Only one student mentioned that she did not invest time to study the course content until a few days before the exam. To conclude, active and regular participation in courses was common to all students, except for one, whose deep approach remained on a high level.

Of the seven students whose deep approach decreased slightly, five described investing time and effort in studying during the course. They actively participated in the lectures and spent a significant amount of time reading the study material. However, two of the students described being less active during the course. One of them stated that he did not have enough time to study on a regular basis and the other student 
stated that she did not have to invest that much time or effort in her studying because the course did not provide much new information.

Only two of the 18 students showing a sharp decrease mentioned studying regularly and actively during the course. Of the remaining 16 students, nine clearly stated that they invested less time and effort in the course than they normally would. Seven of them felt that the course they participated in was not very demanding and they did not have to invest much time or effort in studying, and two students described that their own activity decreased because the course was based on group activities. The other seven students reported that they more generally tend to study actively only when exams approach. One stated that her weak study skills prevented her from studying more effectively during the course. One student worked during the evenings which left her little time for studying.

The results are clear in that investing time and effort in studying during the course was related to the stability of one's deep approach to learning. The less students described being active during the course, the more their deep approach to learning declined. However, the reasons for investing less time varied, being related to particular study habits, weak study skills, working along with studying, or to the challenges the course presented. Most of the students who felt that the course was not very demanding and therefore invested little time and effort, were students from the same theology course. Otherwise no differences were noted between students participating in the different courses as to how much time or effort they devoted to studying.

\subsubsection{Experiences of challenge}

The nine students whose deep approach remained high during the course reported that the courses challenged them positively in one way or another. For four students the course content was challenging, which made them invest more time and effort in studying. Five students did not describe their course as very challenging, but they wanted to thoroughly learn the content, and challenged themselves by reading extra material or analysing the content from different points of view. Thus a challenging learning environment or a student's own desire to thoroughly learn the content, seemed to maintain these three students' deep approach at a high level.

The students showing a slight deep approach decrease experienced the demands of the courses in different ways. Three of the seven students said that the course did not offer them enough of a challenge. For instance, one described the course being more about pondering the course material from different perspectives, because the content was already so familiar.

She would have hoped to learn more new information during the course. On the other hand, four students stated that the courses were in some ways too challenging. For example, one mentioned that the course books were too difficult and that she had to read them many times until gaining some kind of understanding. Another student stated that the course covered too much information, and that he did not always know what he was supposed to study although he felt that he was able to follow the course well. Thus the students showing a slight deep approach decrease experienced both too many and too few challenges, but only to a slight degree. Despite facing challenges or too few of them, most of them actively participated in the lectures and put effort into studying during the course.

Of the 18 students showing a sharp deep approach decrease, the descriptions of eight indicated that the courses were not challenging enough. Some considered that the content was easy, and some thought that the course provided little new information. Conversely, four students mentioned that the courses were too challenging. Two of them had difficulties understanding the course content, while two mentioned that they had difficulties in forming their own view of the content because they acted in groups, which was quite challenging for them. The remaining six students mentioned neither too many nor too few challenges. Students from one theology course stated more often than students from the other courses that the course was not challenging enough, but in the other courses students varied more with respect to how they experienced the challenges the course presented. 
These results suggest that the course 'fit' is important for maintaining one's deep approach at a high level. Either too many or too few challenges seem to lower the level of a deep approach among most students. Kyndt, Dochy, Struyven and Cascallar (2011) similarly showed that task complexity might hinder the application of a deep approach to learning. Similarly, McCune and Entwistle (2011) have emphasised that students need to experience challenging teaching-learning environments that systematically encourage students to focus on personal understanding. However, the results of the present study imply that some students seemed to be able to maintain their deep approach at a relatively high level although the course did not offer many challenges. This accord with the results of Lindblom-Ylänne and Lonka (1999), who identified a cluster of students who were meaning-oriented and who independently found their own way, being immune to the effects of the teaching-learning environment.

\subsubsection{Interest in course content}

Four of the nine students whose deep approach remained high mentioned that the course content was not very interesting. However, two stated that they became more interested in the content during the course. The other mentioned that the way the course was taught promoted her interest, and another expressed that discovering links between the course content and his previous experiences from working life increased his interest. More generally, this student stated that doing things properly is important to him, whether or not he is interested, and that he wanted to succeed and be proud of himself. The remaining five students found the courses more interesting than the two other students, although three of them did not express a strong interest in the course. Despite the level of interest not being high among all of them, all these students showed a commitment to learn and wanted to succeed in their studies. Kyndt et al. (2011) showed that the more student is motivated to study for autonomous reasons such as find a course pleasant, the more they will be inclined to use a deep approach to learning. So although not all students whose deep approach remained at a high level throughout the course described being interested in the course content, they seemed to have a more general motivation to learn for autonomous reasons. Previous research similarly suggest that even though university students may find some content initially uninteresting and their studying may be based on extrinsic motivation, some are through self-regulation processes able to generate their own thoughts, feelings and actions to meet uninteresting study demands (Ryan \& Deci, 2000; Hidi \& Ainley, 2008).

Also students' whose deep approach to learning slightly declined varied with regard to how interesting they found the course content. Six of the seven students described being interested in the content, with only one of them expressing a strong interest. One student said that the course did not interest her much and that her goal was simply to complete it. She also expressed being more interested in the course content at the beginning of the course, but that her level of interest decreased as the course progressed.

Ten of the 18 students showing a sharp deep approach decrease stated that they found the content of the course interesting. However, most of them were not interested beforehand in the content, but became so during the course. On the other hand, eight students found the course content less interesting, but only two of these students mentioned that their goal was only to pass the course because the content was not interesting or useful to them.

Students' interest in the course content did not explain the changes in their deep approach, since both the students whose deep approach decreased, and those whose deep approach did not, described different levels of interest in the course content. However, the students whose deep approach remained high described more often than the others that they create links between different courses, which implies that they try to find the meaning of the courses even if the content does not particularly interest them. Furthermore, these students would invest time and effort in studying even though a course was not of great interest to them, because they would want to understand the content deeply. Interestingly, there were no differences between students participating in the different courses with regard to their interest in the course content.

\subsubsection{Experiences of the course teaching}

The nine students whose deep approach remained high described the teaching of the course in a positive manner. However, only two of them expressed that they were extremely satisfied with the teaching 
and thought that the teaching enhanced their learning. Most students stated that the teaching was fine and that the teacher was pleasant, but they did not mention that the teaching would have considerably enhanced their learning. One student stated that no matter what the teaching is like, he always studies the same way.

The students whose deep approach slightly decreased described their experiences of the teaching in different ways. Two of the seven students described the course teaching in a slightly negative manner. One of them mentioned that the lectures were frustrating, but that she valued the discussions with other students outside the lectures. The other student expressed that the lecturer was agreeable but that the lectures concentrated too much on discussions, with little new information being presented. Three students reported more positive experiences. For example, they mentioned that the teacher had structured the lectures well, was genuinely interested in his students' learning and that there was supportive interaction during the lectures. However, none of the three said that the teaching significantly supported their learning. Two student's experiences of the teaching were rather neutral. They said that the lectures were traditional and not so useful, although they mentioned that the teacher of the course was good.

Ten of the 18 students showing a sharp deep approach decrease were rather satisfied with the teaching of the course. However, only three of these said that the teaching was exceptionally good and the rest expressed milder positive responses. Three students described that the teacher of the course was very pleasant, but still they considered that the teaching did not significantly enhance their learning. Five students had more negative experiences of the teaching: two stated that they did not understand what the teacher had said and that the teaching was boring, and three were not completely satisfied with the teaching method because it was new to them and they did not find themselves comfortable with it. These three students were from a course in educational sciences, where the students studied in groups throughout the whole course. Most of their peers enjoyed the group method, but these three students had some difficulties with it. Otherwise, no clear differences could be detected between students participating in different courses in their experiences of the course teaching.

Interestingly, these results imply, that the experiences of the quality of teaching were not related to deep approach stability or decrease. Most students whose deep approach decreased sharply were satisfied with the teaching and some whose deep approach remained high throughout the course described some negative experiences related to the teaching. Therefore the results support the existence of students who are 'immune' to the teaching-learning environment, as suggested in previous studies by Lindblom-Ylänne \& Lonka (1999), who showed that the study practices of some meaning-oriented students remain unaffected by the learning environment. The results of Baeten et al. (2010), however, showed that students who are satisfied with the quality of a course are more likely to employ a deep approach than students who are less satisfied.

A larger sample of interviewees would be needed to explore in more depth the relationship between students' experiences of teaching and their approaches to learning. Students with lower deep approach scores might be more sensitive to the quality of teaching and the effects of the teaching-learning environment. This could not be confirmed in the present study since all students scored highly at the beginning of the course and thus the sample was highly selected. Another limitation is that the students were categorised into the three change groups according to their scores within only one course. However, during the first measurement the students were asked to consider how they have studied so far, and the interviews were used to improve the reliability of the questionnaire data. Thus the use of a mixed-methods approach enabled a deep and more reliable investigation of the elements affecting students' studying and learning and their disposition to understand. A further limitation concerns the use of different cohorts of students: The data was collected during three different semesters and from both first and second year students, which might affect the results since students representing different cohorts might have diverse experiences of their learning environment. We are able to address some of these limitations in our other studies, since the data collected for our large research project includes a rich variety of qualitative data, e.g. stimulated recall data on assessment of student learning and students' exam papers, observation and video data from the courses as well as large interview data from both students and teachers. 


\subsection{Elements of a 'Disposition to understand for oneself'}

The disposition to understand for oneself, as defined by Entwistle and McCune (Entwistle \& McCune 2009; McCune \& Entwistle, 2011), could not be analysed in detail from the interviews because these focused broadly on studying and learning at the university and on the specific course rather than explicitly on the disposition to understand. However, the strength of our interviews was that they were openended and deep in nature and the students were able to thoroughly describe the elements of their studying and learning they considered to be important. Some elements of having a disposition to understand clearly emerged from the data although the students were not specifically asked about them.

A central element of the disposition to understand is a well-developed use of learning strategies which concentrate on relating ideas, critically using of evidence and attention to detail. These types of learning strategies were identified among most of the interviewed students, although some students who showed sharp decrease in the deep approach described a more narrow use of learning strategies. One component of well-developed learning strategies is a broader focus on the discipline as a whole instead of individual courses or blocks of content. This type of broader focus could be clearly identified among five of the nine students whose deep approach remained high and among three of the seven students whose deep approach slightly decreased. Most of the students whose deep approach sharply decreased described a welldeveloped use of learning strategies, but aiming at gaining a broader view of the discipline as a whole was not emphasised. One student, whose deep approach remained high, described this type of broader focus on the discipline as follows:

"... I enjoy studying and learning hugely. I am very attached to my own major subject, but I would also like to explore what else I can learn here outside my major subject because I want to learn things deeply and broadly. I want to gain thinking and writing skills as well and absorb information from all possible sources." (Male student, Educational sciences)

Secondly, willingness to devote the necessary time, effort and concentration to apply the learning strategies effectively is an essential element of a disposition to understand. Again, the students whose deep approach remained high and most of those showing a slight decrease put a considerable amount of time and effort into studying during the course. However, only a few of the students whose deep approach sharply decreased devoted a good deal of time and effort to studying the content. In the following quotation a student whose deep approach did not decrease describes how he devoted time and effort during the course:

"I attended lectures regularly and took notes. Then, at home I looked at the materials we studied in many different books and I compared it... I tried to combine the new information with the old. I did this during the whole course, which was good, because I was able to keep on track all the time. I didn't read only for the examination, but evenly throughout the course." (Male student, Biosciences)

Furthermore, some of the students showed an 'alertness to the learning context' which is the third important element in a disposition to understand. It is defined as "alertness that monitors the learning processes and strategies in relation to the demands of the task, along with alertness to opportunities provided by the teaching, and indeed the whole learning environment, to further one's understanding". Elements of this type of alertness could be found in five students' interviews whose deep approach did not decrease, in two students' interviews whose deep approach slightly decreased and in one student's interview whose deep approach sharply decreased. However, the data was somewhat thin with regard to analysing alertness to the learning context, which prevented us from further investigating this element. The following quotation offers an example of how alertness to the learning context emerged in our data:

"This bioscience course was very basic, but one had to learn the content deeply. Therefore I did a lot of work and studied the content very well... Once you do that, it helps you later on to understand things. In some courses I have to invest less effort and I don't necessarily understand everything so deeply, but the material in this course needed to be studied well... I 
also study mathematics, physics, chemistry and biochemistry, and it's awesome to notice that some physics and chemistry matters can be combined with biology, and that mathematics is needed in all of them. I want to understand all of these fields." (Male student, Biosciences)

An important finding of our study was that the level of interest towards the content of the courses was not always related to deep approach changes. A low level of interest also characterised students whose deep approach remained high or only decreased slightly. These results suggest that such students have a will to learn even though they might find the course content less interesting. Entwistle and McCune (Entwistle \& McCune 2009; McCune \& Entwistle, 2011) suggest that students with a disposition to understand for oneself have a continuing desire to adopt effortful, deep approaches across a wide range of contexts, and to reach the most satisfying understanding possible. The continuing desire to learn is illustrated in the following quotation:

"I have this constant hunger for information, I always find new things which I want to explore in more depth and I feel I need to find out more about this and that, and sometimes I end up on a number of different paths." (Female student, Educational sciences)

These students also expressed wanting to understand things deeply for their own purposes. Entwistle and McCune (Entwistle \& McCune 2009; McCune \& Entwistle, 2011) note that students showing a disposition to understand feel strongly that they need to understand for themselves, and that they want to demonstrate the depth of their understanding, for example in examination answers. Our results revealed that some of the students showing a slight or no change in their deep approach described that they study as long as it takes to understand the content deeply, and that they explained the content to themselves in their own words, as one student put it:

"I want to understand as deeply as possible, my head can't take pure memorisation. I do mind maps and then I explain the things in my own words to the walls." An attempt to understanding for oneself becomes evident in the following quotation from another student: "I read the course books in a very self-oriented way and I concentrate on the things that are important to me."

McCune and Entwistle suggest that a students' strong commitment to understand may indicate that it has become part of that student's sense of identity as a learner, and so represents a much more stable characteristic than a deep approach. The strong feelings students express suggest that it has become a part of the students' sense of identity as learners (Entwistle \& McCune, 2009). The interview quotations presented in this article contain a substantial number of words implying strong feelings (such as 'hugely', 'hunger for information') which indicate that these students have a strong commitment and disposition to understand. In our data, four of the students showing no deep approach decrease, and one student showing a slight decrease, described this type of strong commitment. As well, the following quotation demonstrates strong feelings ('really', 'overly') when a student describes his studying, which also indicates a solid commitment to understand:

\begin{abstract}
"In every course I take I really want to learn, and not just pass the course. I feel that I really want to understand and use the information. Sometimes there are courses which at first don't seem to be very important, but then I find myself being overly enthusiastic once I get involved with the content...." (Male student, Theology)
\end{abstract}

A challenge related to developing a disposition to understand is that it is, according to McCune and Entwistle (Entwistle \& McCune 2009; McCune \& Entwistle, 2011), a more stable characteristic and less changeable through specific experiences. This was supported by the results of the present study showing that particularly the students whose deep approach did not decrease during the course were unaffected by the teaching-learning environment. McCune and Entwistle emphasise that students need to experience challenging teaching-learning environments that systematically encourage a focus on personal 
understanding. Our results support this view by showing that having too few or too many challenges was mostly related to a decrease in one's deep approach, while positive challenges were related to the stability, or even an increase of one's deep approach. A student whose deep approach decreased sharply describes her perceived lack of challenges in the following way:

"I could have invested more in studying. But somehow I felt that I would remember these things well enough ... I felt that I wouldn't have to write them down in my learning diary immediately after the lectures. I only started the learning diary two days before the deadline." (Female student, Theology)

Thus the central elements of a disposition to understand for oneself clearly emerged from the interviews, but our results imply that only about half of the students whose deep approach remained high, and a few whose deep approach slightly decreased, showed a disposition to understand for oneself. However, a more thorough analysis would require different types of interview questions, which more thoroughly would focus on the disposition to understand. Nevertheless, the deep and open nature of the interviews made it possible to analyse elements of the disposition to understand in the current study as well. In the interviews the students broadly described their studying and learning and these descriptions revealed elements related to the disposition to understand.

The mean age of the three students whose deep approach did not decrease was 30 years. This implies that a stronger commitment to understand might be related to student age as well. Previous studies have also shown that older students are more likely to adopt a deep approach to learning than their younger peers (e.g. Gow \& Kember, 1990).

\section{Conclusions}

In the present study we were able to identify the individual and contextual elements which were related to the stability of or changes in one's deep approach to learning. We identified that the students whose deep approach to learning decreased sharply during the course described problems in their studying and it seemed that at least some of them had exaggerated their deep approach level at the beginning of the course when answering the questionnaire. Thus they did not show as strong commitment to understand as the students whose deep approach did not decrease or decreased only slightly.

The students whose deep approach remained high or decreased only slightly described their studying and learning very similarly, and both individual and contextual elements were identified that logically explained the questionnaire results. The students whose deep approach decreased sharply clearly differed from those showing only slight or no changes in their deep approach with respect to the individual elements. For example, they described more problems in their self-regulation skills, time-management skills and study strategies. However, these students did not differ from the others in terms of their experiences of the teaching or their interest in the course. It therefore seems that the individual elements explained sharp decreases more than the contextual elements did. However, some interviews clearly showed that a lack of challenges or too many challenges decreased the deep approach level. In general, students showing a lack of interest in course content might be inclined to exhibit a disposition to understand for oneself when courses are challenging them in a positive way. Adjusting the level of the course appropriately, then, seems to be a key element in course design. These elements should be further examined among students scoring lower on the deep approach scale.

The results of the study confirm the strength of using in-depth qualitative analysis when examining students' approaches to learning and why they may vary or change. In addition, the study provided new information of the relationship between the deep approach to learning and a disposition to understand for oneself. Our future research will focus on analysing the interviews of students scoring lower on the deep approach to learning scale. 


\section{Keypoints}

- Elements explaining stability or change in the deep approach to learning were explored.

- Individual elements explained the stability or change more than the contextual elements did.

- Not all students showed a strong commitment to understand despite their high score on the deep approach scale.

- Elements of a 'disposition to understand for oneself' were identified among some students.

\section{References}

Baeten, M., Kyndt, E., Struyven, K., \& Dochy, F. (2010). Using student-centred learning environments to stimulate deep approaches to learning: Factors encouraging or discouraging their effectiveness. Educational Research Review, 5, 243-260. doi:10.1016/j.edurev.2010.06.001

Biggs, J. (1987). Student approaches to learning and studying. Camberwell, Vic: Australian Council for Educational Research.

Creswell, J. (2009). Research Design: Qualitative, Quantitative and Mixed Methods Approaches (3rd Edition). London: Sage Publications.

Diseth, A. (2003). Personality and approaches to learning as predictors of academic achievement. European Journal of Personality, 17, 143-155. doi: 10.1002/per.469

Elo, S. \& Kyngäs, H. (2007). The qualitative content analysis process. Journal of Advanced Nursing, 62 (1), 107-115. doi: 10.1111/j.1365-2648.2007.04569.x

Entwistle, N. (2009). Teaching for understanding at university: Deep approaches to learning and distinctive ways of thinking. Basingstoke, Hampshire: Palgrave Macmillan.

Entwistle, N. J., \& McCune, V. (in press). The disposition to understand for oneself at university: Integrating learning processes with motivation and cognition. British Journal of Educational Psychology.

Entwistle, N. J., \& McCune, V. (2009). The disposition to understand for oneself at university and beyond: learning processes, the will to learn and sensitivity to context. In L-F. Zang \& R. J. Sternberg (Eds.), Perspectives on the nature of intellectual styles (pp. 29-62). New York: Springer.

Entwistle, N. \& McCune, V. (2004). The conceptual bases of study strategies inventories in higher education. Educational Psychology Review, 16 (4), 325-345.doi: 10.1007/s10648-004-0003-0

Entwistle, N., \& Ramsden, P. (1983). Understanding student learning. London: Croom Helm.

Flick, U. (2002). An introduction to qualitative research. 2nd ed. London: Sage Publications.

Gijbels, D., Segers, M., \& Struyf, E. (2008). Constructivist learning environments and the (im)possibility to change students' perceptions of assessment demands and approaches to learning. Instructional Science, 36, 431-443. doi: 10.1007/s11251-008-9064-7

Gow, L. \& Kember, D. (1990). Does higher education promote independent learning? Higher Education 19, 307-322. doi: 10.1007/BF00133895

Hailikari, T., Postareff, L,. Tuononen, T., Räisänen, M. \& Lindblom-Ylänne, S. (in press). Students' and teachers' perceptions of fairness in assessment. In C. Kreber, C. Anderson, N. Entwistle, \& J. McArthur (Eds), Advances and Innovations in University Assessment and Feedback. The Edinburgh University Press.

Heikkilä, A., \& Lonka, K. (2006). Studying in higher education: students' approaches to learning, selfregulation, and cognitive strategies. Studies in Higher Education, 31, 99-117. doi: $10.1080 / 03075070500392433$

Heikkilä, A., Niemivirta, M., Nieminen, J., \& Lonka, K. (2011). Interrelations among university students' approaches to learning, regulations of learning, and cognitive and attributional strategies: a person oriented approach. Higher Education, 61, 513-529. doi: 10.1007/s10734-010-9346-2

Hidi, S. \& Ainley, M. (2008). Interest and self-regulation: Relationships between variables that influence learning. In D. Schunk \& B. J. Zimmerman (Eds.), Motivation and self-regulated learning (pp. 77110). Theory, research, and applications. New York: Taylor \& Francis. 
Johnson, R.B, Onwuegbuzie, A.J., \& Turner, L.A. (2007). Toward a Definition of Mixed Methods Research, Journal of Mixed Methods Research, 1(2), 112-133. doi: 10.1177/1558689806298224

Kyndt, E., Dochy, F., Cascallar, E., \& Struyven, K. (2011). The direct and indirect effect of motivation for learning on students' approaches to learning, through perceptions of workload and task complexity. Higher Education Research \& Development, 30, 135-150. doi: 10.1080/07294360.2010.501329

Kyndt, E., Dochy, F., Struyven, K., \& Cascallar, E. (2011). The perception of workload and task complexity and its influence on students' approaches to learning. European Journal of Psychology of Education, 26, 393-415. doi: 10.1007/s10212-010-0053-2

Lietz, P., \& Matthews, B. (2010). The effects of college students' personal values on changes in learning approaches. Research in Higher Education, 51, 65-87. doi: 10.1007/s11162-009-9147-6

Lindblom-Ylänne, S., \& Lonka, K (1999). Individual ways of interacting with the learning environment Are they related to study success? Learning and Instruction, 9, 1-18. doi: 10.1016/S09594752(98)00025-5

Lindblom-Ylänne, S., Parpala, A., \& Postareff, L. (2013). Challenges in analysing change in students' approaches to learning. In V. Donche, J. Richardson, J. Vermunt, \& D. Gijbels (Eds), Learning Patterns in Higher Education. Routledge.

Lonka, K., \& Lindblom-Ylänne, S. (1996). Epistemologies, conceptions of learning, and study practices in medicine and psychology. Higher Education, 31, 5-24. doi: 10.1007/BF00129105

Lonka, K., Olkinuora, E., \& Mäkinen, J. (2004). Aspects and Prospects of Measuring Studying and Learning in Higher Education. Educational Psychology Review, 16 (4), 301-323. doi: 10.1007/s10648-0040002-1

Marton, F. \& Säljö, R. (1976). On qualitative differences in learning: I. Outcome and Process. British Journal of Educational Psychology, 46, 4-11. doi: 10.1111/j.2044-8279.1976.tb02980.x

Marton, F. \& Säljö, R. (1997). Approaches to learning. In F. Marton, D. Hounsell \& N. Entwistle, (Eds.) The experience of learning ( ${ }^{\text {nd }}$ ed., pp. 39-58). Edinburgh, UK: Scottish Academic Press.

Marton, F., Dall'Alba, G., \& Beaty, E. (1993). Conceptions of learning. International Journal of Educational Research, 19, 277-300.

McCune, V., \& Entwistle, N. (2011). Cultivating the disposition to understand in $21^{\text {st }}$ century university education. Learning and Individual Differences, 21, 303-310. doi: 10.1016/j.lindif.2010.11.017

Nieminen, J., Lindblom-Ylänne, S., \& Lonka, K. (2004). The development of study orientations and study success in students of pharmacy. Instructional Science, 32, 387-417. doi: 10.1023/B:TRUC.0000044642.35553.e5

Parpala, A., \& Lindblom-Ylänne, S. (2012). Using a research instrument for developing quality at the university. Quality in Higher Education, 18, 313-328. doi: 10.1080/13538322.2012.733493

Parpala, A., Lindblom-Ylänne, S., Komulainen, E., Litmanen, T., \& Hirsto, L. (2010). Students' approaches to learning and their experiences of the teaching-learning environment in different disciplines. British Journal of Educational Psychology, 80, 269-282. doi: 10.1348/000709909X476946

Patton, M.Q. (1990). Qualitative evaluation and research methods (2nd ed.). London: Sage Publications.

Perkins, D. N., \& Tishman, S. (2001). Dispositional aspects of intelligence. In J. M. Collis \& S. Messick (Eds.), Intelligence and Personality (pp. 233-258). Mahwah, NJ: Lawrence Erlbaum.

Ryan, R. M. \& Deci, E. L. (2000). Intrinsic and extrinsic motivations: Classic definitions and new directions. Contemporary Educational Psychology, 25, 54-67. doi: 10.1006/ceps.1999.1020

Rytkönen, H., Parpala, A., Lindblom-Ylänne, S., Virtanen, V., \& Postareff, L. (2012). Factors affecting bioscience students' academic achievement. Instructional Science, 40, 241-256. doi: 10.1007/s11251-011-9176-3

Schilling, J. (2006). On the pragmatics of qualitative assessment: Designing the process for content analysis. European Journal of Psychological Assessment, 22 (1), 28-37. doi: 10.1027/1015-5759.22.1.28

Struyven, K., Dochy, F., Janssens, S., \& Gielen, S. (2006). On the dynamics of students' approaches to learning: The effects of the teaching/learning environment. Learning and Instruction, 16, 279-294. doi: 10.1016/j.learninstruc.2006.07.001

Trigwell, K., Ellis, R. A., \& Han, F. (2012). Relations between students' approaches to learning, experienced emotions and outcomes of learning. Studies in Higher Education, 37, 811-824. doi: $10.1080 / 03075079.2010 .549220$ 
Trigwell, K., Prosser, M., \& Waterhouse, F. (1999). Relations between teachers' approaches to teaching and students' approaches to learning. Higher Education, 37, 57-70. doi: 10.1023/A:1003548313194

Van Rossum, E. J., Deijkers, R., \& Hamer, R. (1985). Students' learning conceptions and their interpretation of significant educational concepts. Higher Education, 14, 617-641. doi: 10.1007/BF00136501

Vanthournout, G., Donche, V., Gijbels, D. \& Van Petegem, P. (2013). (Dis)similarities in research on learning approaches and learning patterns. In D. Gijbels, V. Donche, J.T.E. Richardson \& J.D. Vermunt (Eds.), Learning Patterns in Higher Education. Dimensions and research perspectives (pp. 11-32). Routledge.

Watters, D., \& Watters, J. (2007). Approaches to learning by students in the biological sciences: Implications for teaching. International Journal of Science Education, 29, 19-43. doi: $10.1080 / 09500690600621282$

Vermunt, J. D. (1998). The regulation of constructive learning processes. British Journal of Educational Psychology, 68, 149-171.doi: 10.1111/j.2044-8279.1998.tb01281.x

Vermunt, J. D.., \& van Rijswijk, F.A.W.M. (1988). Analysis and development of students' skill in selfregulated learning. Higher Education, 170, 647-682.

Vermunt, J. D., \& Verloop, N. (1999). Congruence and friction between learning and teaching. Learning and Instruction, 9, 257-280. doi: 10.1016/S0959-4752(98)00028-0

Watkins, D. A., \& Hattie, J. (1985). A longitudinal study of the approach to learning of Australian tertiary students. Human Learning, 4, 127-142.

Zeegers, P. (2001). Approaches to learning in science: A longitudinal study. British Journal of Educational Psychology, 66, 59-71. doi: 10.1348/000709901158424 